\title{
Effects of Milling in Hydrogen on Magnesium Hydride with a Hydride-Forming Titanium Additive
}

\author{
Myoung Youp SONG ${ }^{1 *}$, Eunho CHOI $^{2}$
}

${ }^{1}$ Division of Advanced Materials Engineering, Hydrogen \& Fuel Cell Research Center, Engineering Research Institute,
Jeonbuk National University, 567 Baekje-daero Deokjin-gu Jeonju, 54896, Republic of Korea
${ }^{2}$ Department of Materials Engineering, Graduate School, Jeonbuk National University, 567 Baekje-daero Deokjin-gu
Jeonju, 54896, Republic of Korea

crossref http://dx.doi.org/10.5755/j02.ms.25056

Received 11 January 2020; accepted 26 May 2020

\begin{abstract}
A hydride-forming element titanium (Ti) was selected as an additive to improve the hydrogen uptake and release properties of $\mathrm{MgH}_{2}$. The hydrogen uptake and release properties of three Ti-added $\mathrm{MgH}_{2}$ alloys [named $\mathrm{MgH}_{2}-\mathrm{xTi}$ $(\mathrm{x}=6,12$, and 15)] prepared by milling in hydrogen (reactive mechanical grinding) were investigated and those of $\mathrm{MgH}_{2}-12 \mathrm{Ti}$ were studied in more detail because it had the highest initial hydrogen uptake and release rates and the largest quantities of hydrogen absorbed and released for $60 \mathrm{~min}$. At the cycle number, $n$, of one $(n=1), \mathrm{MgH}_{2}-12 \mathrm{Ti}$ absorbed $4.01 \mathrm{wt} . \% \mathrm{H}$ for $2.5 \mathrm{~min}$ and $6.39 \mathrm{wt} . \% \mathrm{H}$ for $60 \mathrm{~min}$ at $573 \mathrm{~K}$ in $12 \mathrm{bar}_{2}$, having an effective hydrogen storage capacity of $6.39 \mathrm{wt} \%$. $\mathrm{MgH}_{2}-12 \mathrm{Ti}$ released $0.44 \mathrm{wt} \% \mathrm{H}$ for $2.5 \mathrm{~min}$ and $1.86 \mathrm{wt} . \% \mathrm{H}$ for $60 \mathrm{~min}$ at $593 \mathrm{~K}$ in 1.0 bar $\mathrm{H}_{2} . \gamma-\mathrm{MgH}_{2}, \mathrm{TiH}_{1.924}$, and $\mathrm{MgO}$ were formed during reactive mechanical grinding. We believe that the brute forces and tensile, compressive, or shear stresses, which are applied to the materials during reactive mechanical grinding, introduce imperfections, fabricate cracks, expose fresh and clean surfaces, decrease the particle size, and disperse the additive among the particles. The $\gamma-\mathrm{MgH}_{2}, \mathrm{TiH}_{1.924}$, and $\mathrm{MgO}$ formed during reactive mechanical grinding and their pulverization during reactive mechanical grinding are believed to make these effects stronger.

Keywords: hydrogen absorbing materials, mechanical alloying/milling, scanning electron microscopy (SEM), X-ray diffraction, Ti-added $\mathrm{MgH}_{2}$ alloy.
\end{abstract}

\section{INTRODUCTION}

Many studies have investigated magnesium hydride $\left(\mathrm{MgH}_{2}\right)$ as a promising hydrogen-storage medium for coming transportation, because magnesium hydride has a high hydrogen storage density and is relatively inexpensive. One of the obstacles to applying $\mathrm{MgH}_{2}$ to a practical solid-state hydrogen-storage medium is its slow hydrogenation and dehydrogenation kinetics; high temperature is required for hydrogenation and dehydrogenation and reaction rates are low even at relatively high temperatures.

In order to improve the hydrogenation and dehydrogenation kinetics of magnesium $(\mathrm{Mg})$, many researches have been performed adding catalysts [1-5], using various treatment methods of $\mathrm{Mg}$, and synthesizing Mg-containing compounds [6]. Titanium (Ti) as a catalyst was added to $\mathrm{MgH}_{2}$ [7,8] or $\mathrm{Mg}$ [9-17]. Mechanical milling in argon was used by Liang et al. [1] to prepare $\mathrm{MgH}_{2}-\mathrm{Tm}(\mathrm{Tm}=3 \mathrm{~d}$-transition elements $\mathrm{Ti}, \mathrm{V}, \mathrm{Mn}, \mathrm{Fe}$, $\mathrm{Ni}$ ) nanocomposite powders. The composites with $\mathrm{Ti}$ or $\mathrm{V}$ additives showed very rapid desorption kinetics above $523 \mathrm{~K}$ and absorption kinetics at temperatures as low as $320 \mathrm{~K}$. They reported that the activation energy of desorption for magnesium hydride was reduced drastically, whereas formation enthalpy and entropy of magnesium hydride were not altered by milling with transition metals. $\mathrm{Mg}-\mathrm{Ti}-\mathrm{H}$ FCC hydrides with a face centered cubic (FCC)

\footnotetext{
* Corresponding author. Tel.: +82-63-270-2379; fax: +82-63-270-2386.

E-mail address: songmy@jbnu.ac.kr (M.Y.Song)
}

structure were synthesized directly by Asano et al. [8] from $\mathrm{MgH}_{2}$ and Ti by means of ball milling. They reported that the $\mathrm{Mg}-\mathrm{Ti}-\mathrm{H}$ FCC hydride phases synthesized had chemical formulae of $\mathrm{Mg}_{40} \mathrm{Ti}_{60} \mathrm{H}_{113}$ and $\mathrm{Mg}_{29} \mathrm{Ti}_{71} \mathrm{H}_{57}$, corresponding to the hydrogen contents of 2.9 and 1.4 mass \%, respectively. Titanium isopropoxide ( $\left.\mathrm{Ti}\left[\mathrm{OCH}\left(\mathrm{CH}_{3}\right)_{2}\right]_{4}\right)$ was also added to milled $\mathrm{MgH}_{2}$ by Alsabawi et al. [18] to improve the reaction kinetics of $\mathrm{Mg}$ with hydrogen. They reported that the milling environment had little or no effect on the desorption kinetics in most cases but in some cases, the absorption uptake differed by up to $2 \mathrm{wt} . \%$, depending on the gas used. They argued that all information about the ball-milling processes used, including the gas environment, must be reported. Korablov et al. [9] studied the kinetics and thermodynamics of hydrogenation-dehydrogenation for $\mathrm{Mg}-25 \% \mathrm{TM}(\mathrm{TM}=\mathrm{Ti}$, $\mathrm{Nb}$ or $\mathrm{V}$ ) composites synthesized by reactive ball milling in hydrogen. They reported that for the dehydrogenation process, titanium was the best among the examined additives, as evidenced by its lowest activation energy of the hydrogen desorption $E_{\mathrm{a}}=53.6 \mathrm{~kJ} / \mathrm{mol}$. To overcome sluggish kinetics, Rizo-Acosta et al. [10] added different Ti amounts $(y=0,0.025,0.05,0.1,0.2$, and 0.3$)$ to magnesium to form (1-y) $\mathrm{MgH}_{2}+\mathrm{yTiH}_{2}$ nanocomposites (NC) by reactive ball milling in hydrogen gas. As $\mathrm{Ti}$ amount increased, absorption and desorption kinetics were improved. However, the addition of titanium increased the molar weight of NCs and Ti formed irreversible titanium hydride. Maweja et al. [11] reported that the solid solubility of 50 at $\% \mathrm{Mg}+50$ at $\% \mathrm{Ti}$ powder mixtures was achieved by means of milling in a horizontal high 
energy ball. They reported that FCC and BCC matrices of Ti solid solution existed in $\mathrm{Mg}$ together with traces of an HCP Ti-rich phase after milling at $800 \mathrm{rpm}$ for 48 and $72 \mathrm{~h}$, respectively. The crystallite boundaries acted as preferential sites for the heterogeneous nucleation of the twins and for the formation of the solid solution by release of the lattice strain energy. Korablov et al. [12] synthesized $\mathrm{Mg}-\mathrm{Ti}-\mathrm{H}$ samples with an FCC structure mechanochemically by ball milling in argon atmosphere or under elevated hydrogen pressure, using a metal as the reactant. A ternary $\mathrm{Ti}-\mathrm{Mg}-\mathrm{H}$ compound was not formed using metal hydrides $\left(\mathrm{MgH}_{2}\right.$ and $\left.\mathrm{TiH}_{2}\right)$ as reactants. The amount of $\beta-\mathrm{MgH}_{2}$ increased during the first hydrogen absorption cycle at $573 \mathrm{~K}$ at the expense of the high-pressure polymorph, $\gamma-\mathrm{MgH}_{2}$, and the amount of $\beta-\mathrm{MgH}_{2}$ remained constant during the following hydrogenations. Fast absorption-desorption kinetics at $573 \mathrm{~K}$ and lower onset temperatures for hydrogen release were observed for all investigated samples (lowest onset temperature of desorption of $490 \mathrm{~K})$. In other works, Ti [13, 14], Ti and/or $\mathrm{TiH}_{2}[15,16]$, and $\mathrm{TiH}_{2}$ and $\mathrm{TiO}_{2}$ [17] were added to $\mathrm{Mg}$ to improve the reaction kinetics of $\mathrm{Mg}$ with hydrogen.

Many works to improve the hydrogenation and dehydrogenation kinetics of $\mathrm{Mg}$ were performed by adding titanium (Ti) to $\mathrm{Mg}$ [9-17], but a few works were done by adding $\mathrm{Ti}$ to $\mathrm{MgH}_{2}[7,8]$. In the present work, a hydrideforming element $\mathrm{Ti}$ was chosen as an additive to $\mathrm{MgH}_{2}$ to develop a Mg-based material with a hydrogen storage capacity over $6 \mathrm{wt} \%$. 6, 12, and 15 weight percent Ti were added to $\mathrm{MgH}_{2}$ by milling in hydrogen (reactive mechanical grinding). The effects of milling in hydrogen on $\mathrm{MgH}_{2}$ with a hydride-forming Ti additive were studied. And the hydrogen uptake and release properties of the Tiadded $\mathrm{MgH}_{2}$ alloys [named $\mathrm{MgH}_{2}$-xTi (x = 6, 12, and 15)] were investigated. In particular, the hydrogen uptake and release properties of $\mathrm{MgH}_{2}-12 \mathrm{Ti}$ were studied in more detail because it had the highest initial hydrogen uptake and release rates and the largest quantities of hydrogen absorbed and released for $60 \mathrm{~min}$.

\section{EXPERIMENTAL DETAILS}

$\mathrm{MgH}_{2}$ powder (Magnesium hydride, hydrogen storage grade, Sigma Aldrich.) and titanium ( -3.25 mesh, $99.5 \%$ metal basis, Alfa Aesar) were used as starting materials.

Reactive mechanical grinding (RMG) to prepare $\mathrm{MgH}_{2}-\mathrm{xTi}(\mathrm{x}=6,12$, and 15$)$ was performed in a planetary ball mill (Planetary Mono Mill; Pulverisette 6, Fritsch). Samples with the desired compositions (total weight $=8 \mathrm{~g}$ ) were mixed in a hermetically sealed stainless steel container with 105 hardened steel balls (total weight $=360 \mathrm{~g}$ ); the sample to ball weight ratio was $1 / 45$. All sample handling was performed in a glove box in $\mathrm{Ar}$ in order to prevent oxidation. The disc revolution speed was $250 \mathrm{rpm}$. The mill container (volume of $250 \mathrm{~mL}$ ) was then filled with high purity hydrogen gas ( 12 bar). Milling was performed for $6 \mathrm{~h}$, during which the mill container was refilled with hydrogen every two hours.

The absorbed or released hydrogen quantity was measured as a function of time $(t)$ in nearly constant hydrogen pressures (12 bar $\mathrm{H}_{2}$ for hydrogen uptake and 1.0 bar $\mathrm{H}_{2}$ for hydrogen release) using the volumetric method, with the Sieverts' type hydrogen uptake and release apparatus described previously $[19,20]$. For the hydrogen uptake measurement of the next cycle, vacuum pumping was done for $1.5 \mathrm{~h}$ at $623 \mathrm{~K}$ after every hydrogen release measurement. $0.5 \mathrm{~g}$ of the samples was used for these measurements.

Samples after reactive mechanical grinding and after hydrogen uptake-release cycling were characterized by Xray diffraction (XRD) with $\mathrm{Cu} \mathrm{K} \alpha$ radiation, using a Rigaku D/MAX 2500 powder diffractometer. The microstructures of the powders were observed using a JSM-5900 scanning electron microscope (SEM) operated at $20 \mathrm{kV}$.

\section{RESULTS AND DISCUSSION}

The quantities of hydrogen absorbed $\left(H_{\mathrm{a}}\right)$ and desorbed (released) $\left(H_{\mathrm{d}}\right)$ were calculated using the sample weight as a standard and expressed in the unit of wt. $\% \mathrm{H}$. The initial hydrogen uptake and release rates (wt.\% H/min) were defined as the quantities of hydrogen absorbed and released, respectively, for the first $2.5 \mathrm{~min}$ divided by $2.5 \mathrm{~min}$. The hydrogen uptake rate and the hydrogen release rate were defined as the tangents of the curves at given times. The quantities of hydrogen absorbed and released for $t$ min were expressed as $H_{\mathrm{a}}(t$ min $)$ and $H_{\mathrm{d}}(t$ min), respectively.

Fig. 1 shows the variation in the $H_{\mathrm{a}}$ vs. time $t$ curve with $\mathrm{x}$ at $573 \mathrm{~K}$ in 12 bar $\mathrm{H}_{2}$ at the cycle number, $n$, of one $(n=1)$ for $\mathrm{MgH}_{2}-\mathrm{xTi}(\mathrm{x}=6,12$, and 15) samples. The initial hydrogen uptake rates of the samples are quite high and the hydrogen uptake rate becomes very low after about 15 min. $\mathrm{MgH}_{2}-12 \mathrm{Ti}$ has the highest initial hydrogen uptake rate and the largest quantity of hydrogen absorbed for $60 \mathrm{~min}, H_{\mathrm{a}}(60 \mathrm{~min})$, followed in order by $\mathrm{MgH}_{2}-6 \mathrm{Ti}$ and $\mathrm{MgH}_{2}-15 \mathrm{Ti}$. $\mathrm{MgH}_{2}-12 \mathrm{Ti}$ absorbs $4.01 \mathrm{wt} . \% \mathrm{H}$ for $2.5 \mathrm{~min}$ and $6.39 \mathrm{wt} . \% \mathrm{H}$ for $60 \mathrm{~min}$. Table 1 shows the variation of $H_{\mathrm{a}}$ with $t$ at $573 \mathrm{~K}$ in 12 bar $\mathrm{H}_{2}$ at $n=1$ for $\mathrm{MgH}_{2}-\mathrm{xTi}$ $(\mathrm{x}=6,12$, and 15).

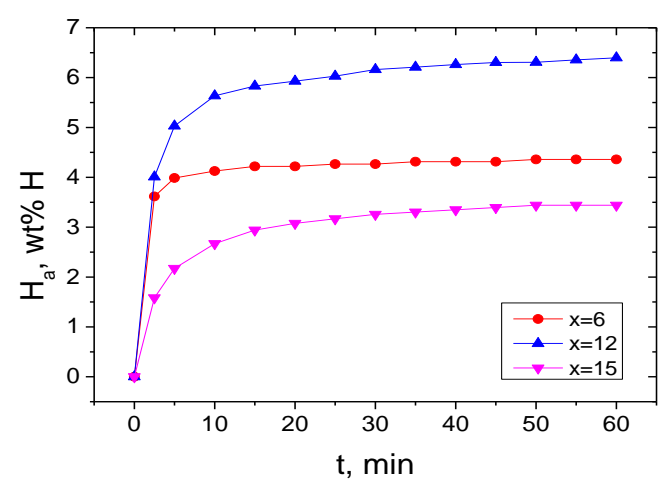

Fig. 1. Variation in the $H_{\mathrm{a}}$ vs. time $t$ curve with $\mathrm{x}$ at $573 \mathrm{~K}$ in 12 bar $\mathrm{H}_{2}$ at the first cycle $(n=1)$ for $\mathrm{MgH}_{2}-\mathrm{xTi}(\mathrm{x}=6,12$, and 15) samples

Table 1. Variation of $H_{\mathrm{a}}(\mathrm{wt} . \% \mathrm{H})$ with $t(\mathrm{~min})$ at $573 \mathrm{~K}$ in 12 bar $\mathrm{H}_{2}$ at $n=1 \sim 4$ for $\mathrm{MgH}_{2}-\mathrm{xTi}(\mathrm{x}=6,12$, and 15)

\begin{tabular}{|c|c|c|c|c|c|}
\hline & $2.5 \min$ & $5 \min$ & $10 \min$ & $30 \min$ & $60 \min$ \\
\hline $\mathrm{x}=6$ & 3.61 & 3.99 & 4.12 & 4.27 & 4.36 \\
\hline $\mathrm{x}=12$ & 4.01 & 5.03 & 5.63 & 6.16 & 6.39 \\
\hline $\mathrm{x}=15$ & 1.58 & 2.17 & 2.67 & 3.26 & 3.44 \\
\hline
\end{tabular}


The variation in the $H_{\mathrm{d}}$ vs. $t$ curve with $\mathrm{x}$ at $573 \mathrm{~K}$ in 1.0 bar $\mathrm{H}_{2}$ at $n=1$ for $\mathrm{MgH}_{2}-\mathrm{xTi} \quad(\mathrm{x}=6,12$, and 15) samples is shown in Fig. 2. The initial hydrogen release rates are slightly high and the hydrogen release rates at $2.5 \mathrm{~min}$ are low. The slightly high initial hydrogen release rate is attributed to the slightly large quantities of hydrogen desorbed from the surfaces of the particles and released from the $\mathrm{Mg}-\mathrm{H}$ solid solution. $\mathrm{MgH}_{2}-15 \mathrm{Ti}$ has very low hydrogen release rate after $2.5 \mathrm{~min}$. $\mathrm{MgH}_{2}-12 \mathrm{Ti}$ and $\mathrm{MgH}_{2}-$ $6 \mathrm{Ti}$ have low and nearly constant hydrogen release rates from $5 \mathrm{~min}$ to $60 \mathrm{~min}$. $\mathrm{MgH}_{2}-12 \mathrm{Ti}$ has the highest initial hydrogen release rate and the largest quantity of hydrogen released for $60 \mathrm{~min}, H_{\mathrm{d}}(60 \mathrm{~min})$. Table 2 shows the variation of $H_{\mathrm{d}}$ with $t$ at $573 \mathrm{~K}$ in 1.0 bar $H_{2}$ at $n=1$ for $\mathrm{MgH}_{2}-\mathrm{xTi}(\mathrm{x}=6,12$, and 15).

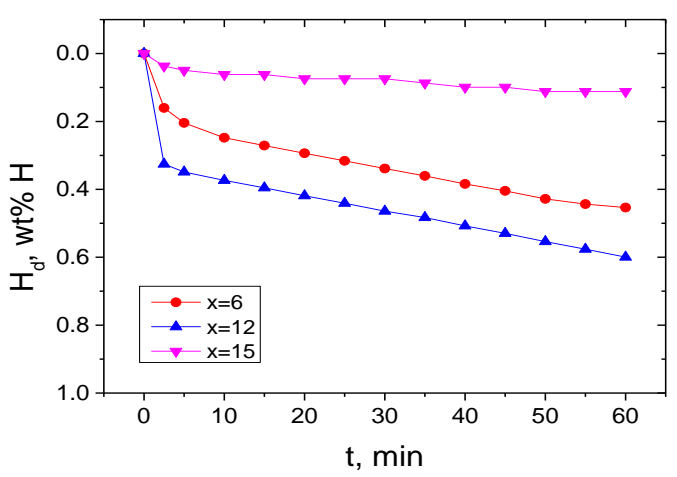

Fig. 2. Variation in the $H_{\mathrm{d}}$ vs. $t$ curve with $\mathrm{x}$ at $573 \mathrm{~K}$ in 1.0 bar $\mathrm{H}_{2}$ at $n=1$ for $\mathrm{MgH}_{2}-\mathrm{xTi}(\mathrm{x}=6,12$, and 15) samples

Table 2. Variation of $H_{\mathrm{d}}(\mathrm{wt} . \% \mathrm{H})$ with $t(\mathrm{~min})$ at $573 \mathrm{~K}$ in $1.0 \mathrm{bar}$ $\mathrm{H}_{2}$ at $n=1 \sim 4$ for $\mathrm{MgH}_{2}$-xTi $(\mathrm{x}=6,12$, and 15)

\begin{tabular}{|c|c|c|c|c|c|}
\hline & $2.5 \min$ & $5 \min$ & $10 \min$ & $30 \min$ & $60 \min$ \\
\hline $\mathrm{x}=6$ & 0.16 & 0.20 & 0.25 & 0.34 & 0.45 \\
\hline $\mathrm{x}=12$ & 0.33 & 0.35 & 0.37 & 0.46 & 0.59 \\
\hline $\mathrm{x}=15$ & 0.04 & 0.05 & 0.06 & 0.07 & 0.11 \\
\hline
\end{tabular}

Fig. 1 and Fig. 2 show that among the $\mathrm{MgH}_{2}-\mathrm{xTi}$ ( $\mathrm{x}=6,12$, and 15) samples, $\mathrm{MgH}_{2}-12 \mathrm{Ti}$ has the highest initial hydrogen uptake and release rates and the largest $H_{\mathrm{a}}$ (60 min) and $H_{\mathrm{d}}(60 \mathrm{~min})$. The hydrogen uptake and release properties of $\mathrm{MgH}_{2}-12 \mathrm{Ti}$ were studied in more detail.

Fig. 3 shows the SEM micrographs of $\mathrm{MgH}_{2}-6 \mathrm{Ti}$, $\mathrm{MgH}_{2}-12 \mathrm{Ti}$, and $\mathrm{MgH}_{2}-15 \mathrm{Ti}$ after reactive mechanical milling. The particle sizes are not homogeneous. The particles are agglomerated. $\mathrm{MgH}_{2}-12 \mathrm{Ti}$ has the smallest agglomerates, followed in order by $\mathrm{MgH}_{2}-6 \mathrm{Ti}$ and $\mathrm{MgH}_{2}-15 \mathrm{Ti}$.

The variation in the $H_{\mathrm{a}}$ vs. $t$ curve with cycle number, $n$, at $573 \mathrm{~K}$ in 12 bar $\mathrm{H}_{2}$ for $\mathrm{MgH}_{2}-12 \mathrm{Ti}$ is shown in Fig. 4. At $n=1$, the initial hydrogen uptake rate is quite high and the quantity of hydrogen absorbed for $60 \mathrm{~min}, H_{\mathrm{a}}(60 \mathrm{~min})$, is quite large. At $n=1$, the hydrogen uptake rate decreases gradually as the reaction time elapses and is very low after 20 min. As $\mathrm{n}$ increases from one to three, the initial hydrogen uptake rate and $H_{\mathrm{a}}(60 \mathrm{~min})$ decrease rapidly. From $n=3$ to $n=4$, the initial hydrogen uptake rate and $H_{\mathrm{a}}$ (60 min) increase. During vacuum pumping at $623 \mathrm{~K}$ after the release measurement, residual hydrogen release and coalescence of cracks inside the particles can occur. The higher initial hydrogen uptake rate and the larger $H_{\mathrm{a}}$ (60 min) at $n=4$ than at $n=3$ is thought to result from shorter vacuum pumping time $(1.5 \mathrm{~h})$ after the release measurement of the third cycle than that $(6 \mathrm{~h})$ after the release measurement of the second cycle.

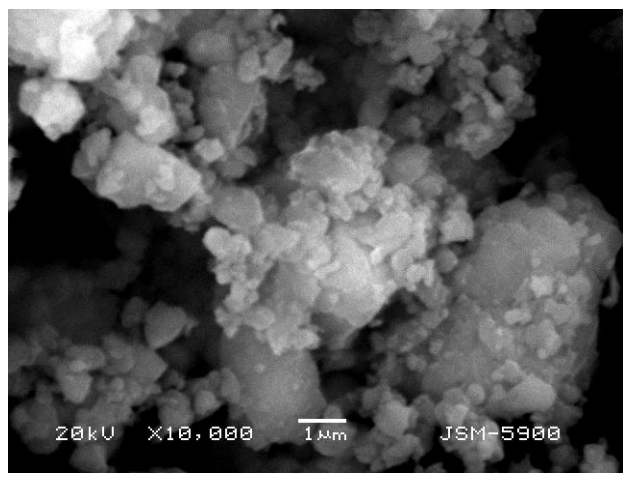

a

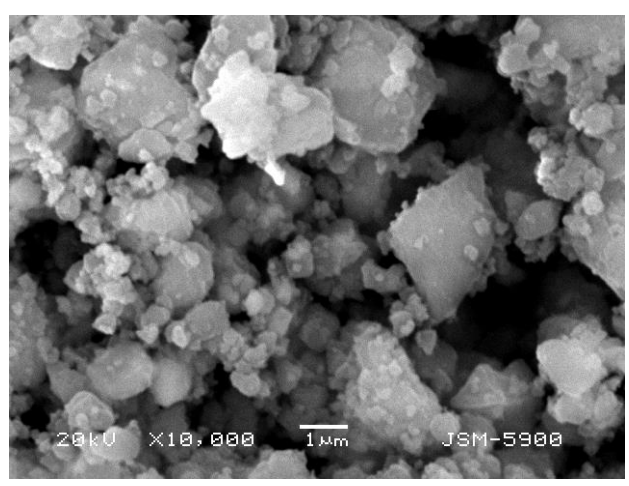

b

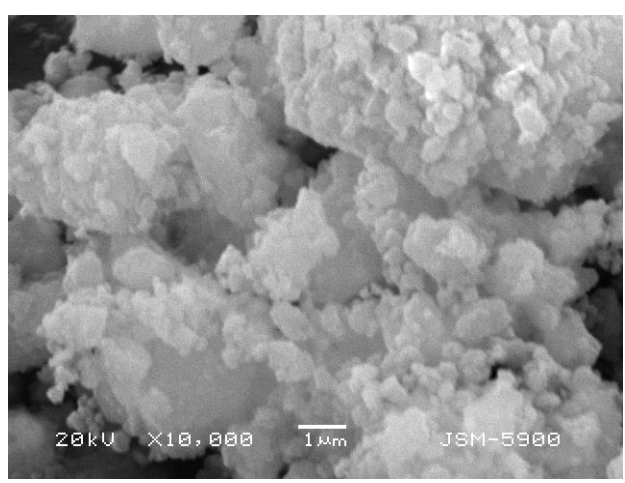

c

Fig. 3. SEM micrographs of; $\mathrm{a}-\mathrm{MgH}_{2}-6 \mathrm{Ti} ; \mathrm{b}-\mathrm{MgH}_{2}-12 \mathrm{Ti}$; $\mathrm{c}-\mathrm{MgH}_{2}-15 \mathrm{Ti}$ after reactive mechanical grinding

The general decreases in the initial hydrogen uptake rate and $H_{\mathrm{a}}(60 \mathrm{~min})$ with the cycle number are attributed to coalescence of cracks inside the particles because the sample was maintained at the relatively high temperatures, $573 \mathrm{~K}$ during hydrogen uptake-release cycling and $623 \mathrm{~K}$ during vacuum pumping. The longer vacuum pumping time $(6 \mathrm{~h})$ after the release measurement of the second cycle than that $(1.5 \mathrm{~h})$ after the release measurement of the third cycle is thought to have caused the lower initial hydrogen uptake rate and the smaller $H_{\mathrm{a}}(60 \mathrm{~min})$ at $n=3$ than at $n=4$ due to coalescence of cracks inside the particles. At $n=1, \mathrm{MgH}_{2}-12 \mathrm{Ti}$ absorbs $4.00 \mathrm{wt} \% \mathrm{H}$ for 
$2.5 \mathrm{~min}$ and $6.39 \mathrm{wt} . \% \mathrm{H}$ for $60 \mathrm{~min}$. At $n=4, \mathrm{MgH}_{2}-12 \mathrm{Ti}$ absorbs $1.66 \mathrm{wt} . \% \mathrm{H}$ for $2.5 \mathrm{~min}$ and $3.35 \mathrm{wt} \% \mathrm{H}$ for $60 \mathrm{~min}$.

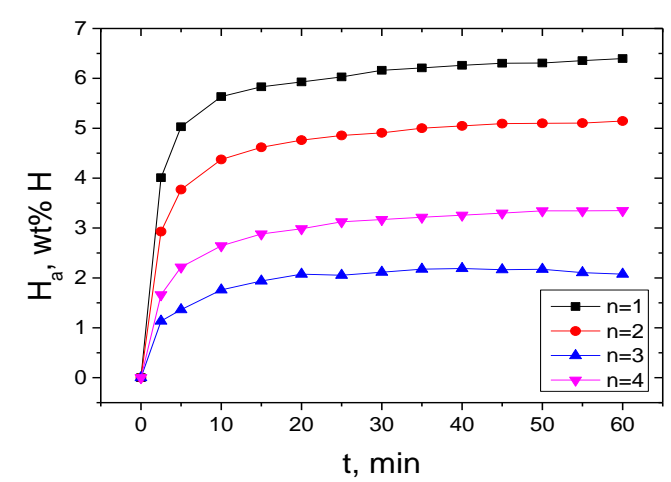

Fig. 4. Variation in the $H_{\mathrm{a}}$ vs. $t$ curve with cycle number, $n$, at $573 \mathrm{~K}$ in 12 bar $\mathrm{H}_{2}$ for $\mathrm{MgH}_{2}-12 \mathrm{Ti}$

We define the quantity of hydrogen absorbed for $60 \mathrm{~min}$ as the effective hydrogen storage capacity. $\mathrm{MgH}_{2}-$ $12 \mathrm{Ti}$ has an effective hydrogen storage capacity of 6.39 wt. $\%$ at $573 \mathrm{~K}$ in 12 bar $\mathrm{H}_{2}$ at $n=1$.

The variation in the $H_{\mathrm{d}}$ vs. $t$ curve with cycle number, $n$, at $573 \mathrm{~K}$ in 1.0 bar $\mathrm{H}_{2}$ for $\mathrm{MgH}_{2}-12 \mathrm{Ti}$ is shown in Fig. 5 . At $n=1$, the initial hydrogen release rate is slightly high and the quantity of hydrogen released for $60 \mathrm{~min}, H_{\mathrm{d}}$ (60 $\mathrm{min}$ ), is small. As $n$ increases from one to three, the initial hydrogen release rate and $H_{\mathrm{d}}(60 \mathrm{~min})$ decrease. From $n=3$ to $n=4$, the initial hydrogen release rate and $H_{\mathrm{d}}(60 \mathrm{~min})$ increase. The higher initial hydrogen release rate and the larger $H_{\mathrm{d}}(60 \mathrm{~min})$ at $n=4$ than at $n=3$ result from larger $H_{\mathrm{a}}(60 \mathrm{~min})$ at $n=4$ than at $n=3$. The general decreases in the initial hydrogen release rate and $H_{\mathrm{d}}$ (60 min) with the cycle number are also attributed to the coalescence of cracks inside the particles because the sample was maintained at relatively high temperatures $573 \mathrm{~K}$ and $623 \mathrm{~K}$ during hydrogen uptake-release cycling. After $5 \mathrm{~min}$, the hydrogen release rates are nearly constant. At $n=1, \mathrm{MgH}_{2}-12 \mathrm{Ti}$ releases $0.33 \mathrm{wt}$. $\% \mathrm{H}$ for $2.5 \mathrm{~min}$ and 0.59 wt. $\% \mathrm{H}$ for $60 \mathrm{~min}$. At $n=4, \mathrm{MgH}_{2}-12 \mathrm{Ti}$ releases $0.28 \mathrm{wt} . \% \mathrm{H}$ for $2.5 \mathrm{~min}$ and $0.53 \mathrm{wt} . \% \mathrm{H}$ for $60 \mathrm{~min}$.

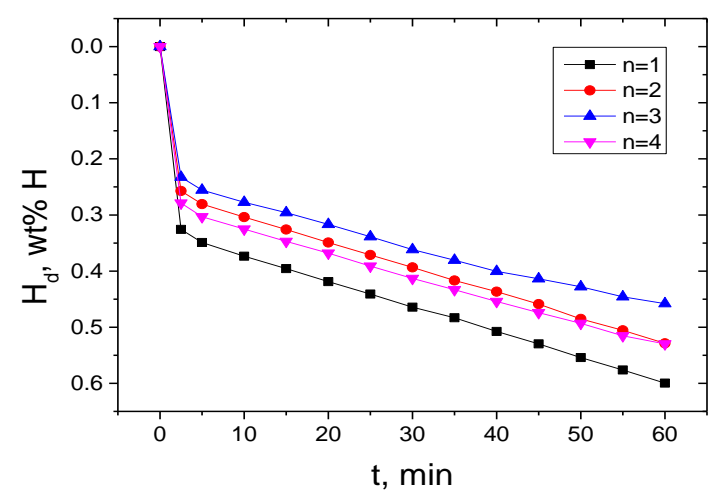

Fig. 5. Variation in the $H_{\mathrm{d}}$ vs. $t$ curve with $n$ at $573 \mathrm{~K}$ in 1.0 bar $\mathrm{H}_{2}$ for $\mathrm{MgH}_{2}-12 \mathrm{Ti}$

Fig. 6 shows the variation in the $H_{\mathrm{a}}$ vs. $t$ curve with cycle number, $n$, at $593 \mathrm{~K}$ in 12 bar $\mathrm{H}_{2}$ for $\mathrm{MgH}_{2}-12 \mathrm{Ti}$. At $n=1$, the initial hydrogen uptake rate is quite high and the quantity of hydrogen absorbed for $60 \mathrm{~min}, H_{\mathrm{a}}(60 \mathrm{~min})$, is quite large. As $n$ increases from one to four, the initial hydrogen uptake rate and $H_{\mathrm{a}}(60 \mathrm{~min})$ decrease. The change in $H_{\mathrm{a}}(60 \mathrm{~min})$ with $n$ at $593 \mathrm{~K}$ is relatively small, compared with that at $573 \mathrm{~K}$. The hydrogen uptake rate decreases gradually as the reaction time elapses and is very low after $20 \mathrm{~min}$. At $n=1, \mathrm{MgH}_{2}-12 \mathrm{Ti}$ absorbs 3.06 wt. $\%$ $\mathrm{H}$ for $2.5 \mathrm{~min}$ and $5.39 \mathrm{wt} \% \mathrm{H}$ for $60 \mathrm{~min}$. At $n=4$, $\mathrm{MgH}_{2}-12 \mathrm{Ti}$ absorbs $2.69 \mathrm{wt} \% \mathrm{H}$ for $2.5 \mathrm{~min}$ and $4.67 \mathrm{wt} \% \mathrm{H}$ for $60 \mathrm{~min}$. Table 3 shows the variation of $H_{\mathrm{a}}$ with $t$ at $593 \mathrm{~K}$ in 12 bar $\mathrm{H}_{2}$ at $n=1 \sim 4$ for $\mathrm{MgH}_{2}-12 \mathrm{Ti}$. The initial hydrogen uptake rate and $H_{\mathrm{a}}(60 \mathrm{~min})$ at $n=1$ at $593 \mathrm{~K}$ are lower and smaller, respectively, than those at $n=1$ at $573 \mathrm{~K}$. The increase in temperature increases the diffusion rate of hydrogen atoms but decreases the driving force for hydrogenation (the difference between the applied hydrogen pressure and the equilibrium plateau pressure at a given temperature). We believe that the effect of the latter predominates over that of the former, leading to decreases in the initial hydrogen uptake rate and $H_{\mathrm{a}}$ (60 $\min$ ) at $n=1$ at $593 \mathrm{~K}$.

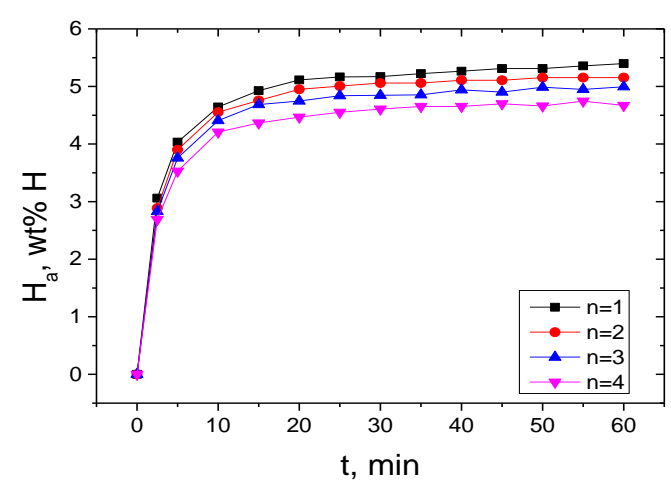

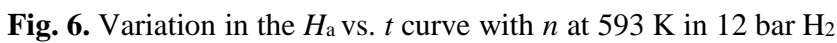
for $\mathrm{MgH}_{2}-12 \mathrm{Ti}$

The variation in the $H_{\mathrm{d}}$ vs. $t$ curve with cycle number, $n$, at $593 \mathrm{~K}$ in 1.0 bar $\mathrm{H}_{2}$ for $\mathrm{MgH}_{2}-12 \mathrm{Ti}$ is shown in Fig. 7. At $n=1$, the initial hydrogen release rate is slightly high and the quantity of hydrogen released for $60 \mathrm{~min}, H_{\mathrm{d}}$ (60 min), is larger, compared with $H_{\mathrm{d}}(60 \mathrm{~min})$ at $573 \mathrm{~K}$. As $n$ increases from one to four, the initial hydrogen release rate and $H_{\mathrm{d}}(60 \mathrm{~min})$ decrease.

Table 3. Variation of $H_{\mathrm{a}}(\mathrm{wt} . \% \mathrm{H})$ with $t(\min )$ at $593 \mathrm{~K}$ in $12 \mathrm{bar}$ $\mathrm{H}_{2}$ at $n=1 \sim 4$ for $\mathrm{MgH}_{2}-12 \mathrm{Ti}$

\begin{tabular}{|c|c|c|c|c|c|}
\hline & $2.5 \min$ & $5 \min$ & $10 \min$ & $30 \min$ & $60 \min$ \\
\hline $\mathrm{n}=1$ & 3.06 & 4.03 & 4.64 & 5.17 & 5.39 \\
\hline $\mathrm{n}=2$ & 2.89 & 3.90 & 4.55 & 5.06 & 5.15 \\
\hline $\mathrm{n}=3$ & 2.82 & 3.77 & 4.41 & 4.84 & 4.99 \\
\hline $\mathrm{n}=4$ & 2.69 & 3.53 & 4.21 & 4.01 & 4.67 \\
\hline
\end{tabular}

From $n=1$ to $n=2, H_{\mathrm{d}}(60 \mathrm{~min})$ decreases sharply and from $n=2$ to $n=4, H_{\mathrm{d}}(60 \mathrm{~min})$ decreases slowly. At $2.5 \mathrm{~min}$, the hydrogen release rates are low. The hydrogen release rates increase gradually after $2.5 \mathrm{~min}$ and are quite high at $50 \mathrm{~min}$. At $n=1, \mathrm{MgH}_{2}-12 \mathrm{Ti}$ releases 0.44 wt. $\% \mathrm{H}$ for $2.5 \mathrm{~min}$ and $1.86 \mathrm{wt} . \% \mathrm{H}$ for $60 \mathrm{~min}$. At $n=4$, $\mathrm{MgH}_{2}-12 \mathrm{Ti}$ releases $0.37 \mathrm{wt} . \% \mathrm{H}$ for $2.5 \mathrm{~min}$ and $1.44 \mathrm{wt} \% \mathrm{H}$ for $60 \mathrm{~min}$. Table 4 shows the of $H_{\mathrm{d}}$ with $t$ at $593 \mathrm{~K}$ in 1.0 bar $\mathrm{H}_{2}$ at $n=1 \sim 4$ for $\mathrm{MgH}_{2}-12 \mathrm{Ti}$. The initial 
hydrogen release rate and $H_{\mathrm{d}}(60 \mathrm{~min})$ at $593 \mathrm{~K}$ are higher and larger, respectively, than those at $573 \mathrm{~K}$. The increase in temperature increases not only the diffusion rate of hydrogen atoms but also the driving force for dehydrogenation (the difference between the equilibrium plateau pressure at a given temperature and the applied hydrogen pressure), leading to increases in the initial hydrogen release rate and $H_{\mathrm{d}}(60 \mathrm{~min})$ at $593 \mathrm{~K}$.

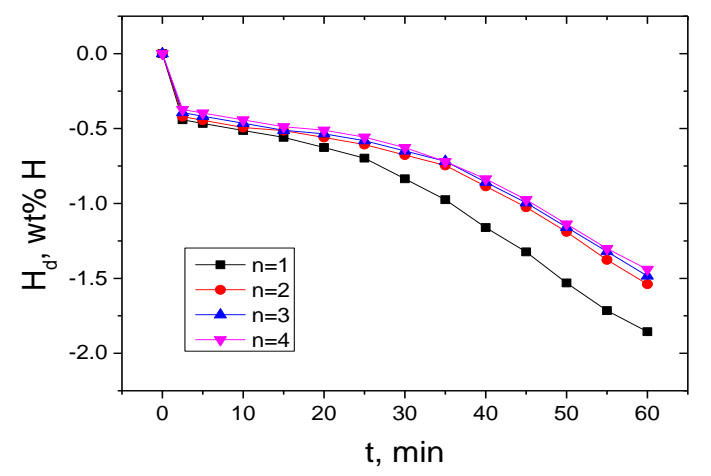

Fig. 7. Variation in the $H_{\mathrm{d}}$ vs. $t$ curve with $n$ at $593 \mathrm{~K}$ in 1.0 bar $\mathrm{H}_{2}$ for $\mathrm{MgH}_{2}-12 \mathrm{Ti}$

Table 4. Variation of $H_{\mathrm{d}}(\mathrm{wt} \% H)$ with $t$ (min) at $593 \mathrm{~K}$ in $1.0 \mathrm{bar}$ $\mathrm{H}_{2}$ at $n=1 \sim 4$ for $\mathrm{MgH}_{2}-12 \mathrm{Ti}$

\begin{tabular}{|c|c|c|c|c|c|}
\hline & $2.5 \min$ & $5 \min$ & $10 \min$ & $30 \min$ & $60 \min$ \\
\hline $\mathrm{n}=1$ & 0.44 & 0.57 & 0.51 & 0.84 & 1.86 \\
\hline $\mathrm{n}=2$ & 0.42 & 0.44 & 0.49 & 0.68 & 1.54 \\
\hline $\mathrm{n}=3$ & 0.39 & 0.42 & 0.46 & 0.65 & 1.48 \\
\hline $\mathrm{n}=4$ & 0.37 & 0.39 & 0.44 & 0.63 & 1.44 \\
\hline
\end{tabular}

Fig. 8 shows the SEM micrographs at various magnifications of $\mathrm{MgH}_{2}-12 \mathrm{Ti}$ after reactive mechanical grinding. Particle size is not homogeneous; some particles are fine and some particles are large. These particles form agglomerates. Some large particles have flat surfaces with few fine particles on the surfaces.

The SEM micrographs at various magnifications of $\mathrm{MgH}_{2}-12 \mathrm{Ti}$ dehydrogenated in 1.0 bar $\mathrm{H}_{2}$ at $n=4$ are shown in Fig. 9. Particle size is not homogeneous, either; some particles are fine and some particles are large. However, this sample has more homogeneous particle size than the sample after reactive mechanical grinding.
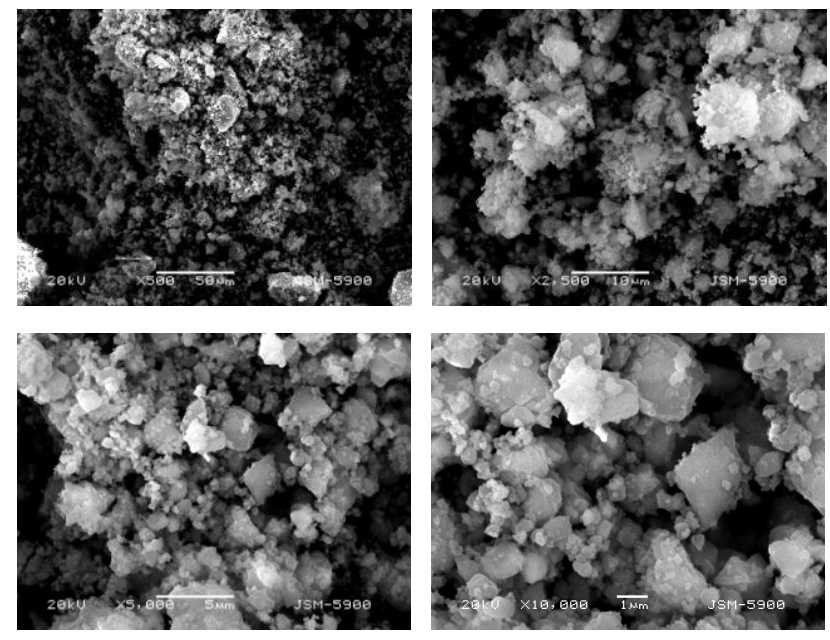

Fig. 8. SEM micrographs at various magnifications of $\mathrm{MgH}_{2}-$ $12 \mathrm{Ti}$ after reactive mechanical grinding
These particles form agglomerates. Particles on the surfaces of the particles are smaller than those of the sample after reactive mechanical grinding. The agglomerates are larger than those of the sample after reactive mechanical grinding.
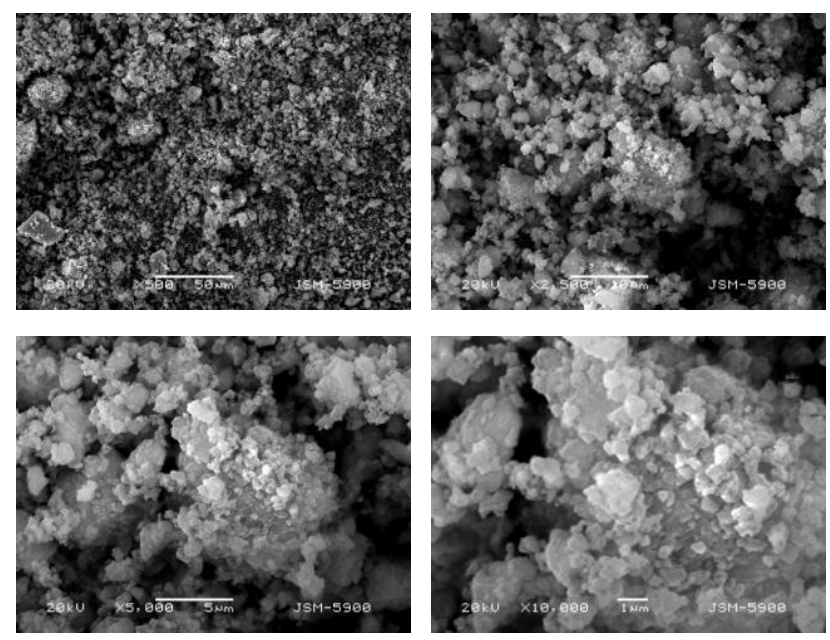

Fig. 9. SEM micrographs at various magnifications of $\mathrm{MgH}_{2}-12 \mathrm{Ti}$ dehydrogenated at $593 \mathrm{~K}$ in $1.0 \mathrm{bar} \mathrm{H}_{2}$ at $n=4$ after hydrogen uptake-release cycling at $593 \mathrm{~K}$

Fig. 10 shows the XRD pattern of $\mathrm{MgH}_{2}-12 \mathrm{Ti}$ after reactive mechanical grinding. The $\mathrm{MgH}_{2}-12 \mathrm{Ti}$ after reactive mechanical grinding contains a large amount of $\beta$ $\mathrm{MgH}_{2}$ and small amounts of $\mathrm{Mg}, \gamma-\mathrm{MgH}_{2}, \mathrm{TiH}_{1.924}$, and $\mathrm{MgO}$. This shows that most of the sample is hydrogenated to $\beta-\mathrm{MgH}_{2}$ and that $\mathrm{TiH}_{1.924}$ is formed by the reaction of $\mathrm{Ti}$ with hydrogen during milling in hydrogen. Liang et al. [7] reported that $\mathrm{TiH}_{2}$ was formed after $20 \mathrm{~h}$ of milling of $\mathrm{MgH}_{2}$ with Ti. Biasetti et al. $[15,16]$ reported the formation of $\mathrm{TiH}_{2}$ after milling $\mathrm{Mg}$ with $\mathrm{Ti}$ in hydrogen.

The XRD pattern of $\mathrm{MgH}_{2}-12 \mathrm{Ti}$ dehydrogenated at $593 \mathrm{~K}$ in 1.0 bar $\mathrm{H}_{2}$ at $n=4$ after hydrogen uptake-release cycling at $593 \mathrm{~K}$ is shown in Fig. 11. The $\mathrm{MgH}_{2}-12 \mathrm{Ti}$ dehydrogenated at $593 \mathrm{~K}$ in 1.0 bar $\mathrm{H}_{2}$ at $n=4$ contains large amounts of $\beta-\mathrm{MgH}_{2}$ and $\mathrm{Mg}$ and very small amounts of $\mathrm{MgO}, \mathrm{TiH}_{1.924}$, and $\mathrm{Mg}(\mathrm{OH})_{2}$. The existence of large amounts of $\beta-\mathrm{MgH}_{2}$ indicates that most of the hydrides in the sample are not decomposed.

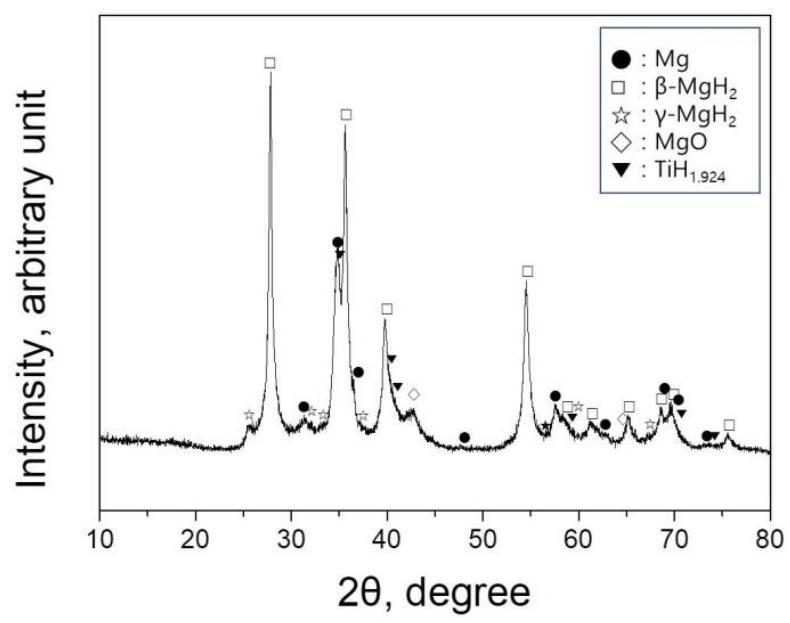

Fig. 10. XRD pattern of $\mathrm{MgH}_{2}-12 \mathrm{Ti}$ after reactive mechanical grinding 
$\mathrm{TiH}_{1.924}$ remains undecomposed, but $\gamma-\mathrm{MgH}_{2}$ is not present, after the sample was dehydrogenated in $1.0{\text { bar } \mathrm{H}_{2}}$ at $n=4$. We believe that $\mathrm{MgO}$ was formed by the reaction with oxygen adsorbed on the particle surfaces while the sample was treated to obtain the XRD pattern. $\mathrm{Mg}(\mathrm{OH})_{2}$ is thought to have been formed by the reaction of $\mathrm{MgO}$ with the water vapor adsorbed on the particle surfaces during treating the samples to obtain the XRD pattern. Liang et al. [7] reported that $\mathrm{TiH}_{2}$ phase did not decompose after desorption at $573 \mathrm{~K}$ in 0.15 bar $\mathrm{H}_{2}$. Biasetti et al. $[15,16]$ reported that the $\mathrm{TiH}_{2}$ formed after milling remained as a stable phase after cycling. The addition of $12 \mathrm{wt} \% \mathrm{Ti}$ to $\mathrm{MgH}_{2}$ decreased the theoretical hydrogen storage capacity from $7.60 \mathrm{wt} . \%$ to $7.15 \mathrm{wt} \%$. Some hydrogen is "trapped" in the form of $\mathrm{TiH}_{1.924}$. The formation of $\mathrm{TiH}_{1.924}$ decreases partly the practical reversible quantity of hydrogen (hydrogen absorbed and then released).

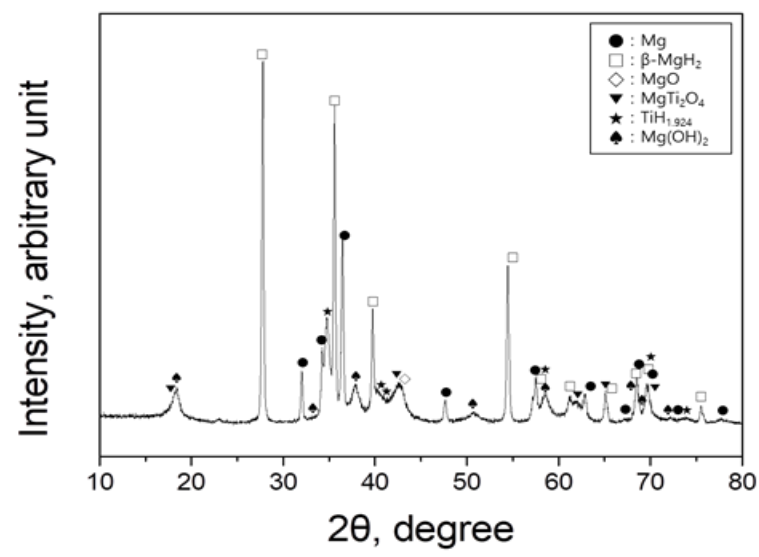

Fig. 11. XRD pattern of $\mathrm{MgH}_{2}-12 \mathrm{Ti}$ dehydrogenated at $593 \mathrm{~K}$ in 1.0 bar $\mathrm{H}_{2}$ at $n=4$ after hydrogen uptake-release cycling at $593 \mathrm{~K}$

During reactive mechanical grinding of $\mathrm{MgH}_{2}$ with Ti, brute forces and tensile, compressive, or shear stresses are applied to the material. These forces and stresses are believed to introduce imperfections, fabricate cracks, expose fresh and clean surfaces, decrease the particle size [21-26], and disperse the additive among the particles. Introduction of imperfections is considered to ease nucleation. We believe that fabricating cracks and exposing fresh and clean surfaces increase the reactivity of particles with hydrogen. Decreasing the particle size is deemed to decrease the diffusion distance of hydrogen atoms [21-26]. We believe that dispersing the additive and materials produced during reactive mechanical grinding among the particles prevents the particles from being coalesced during hydrogen uptake-release cycling. Decreasing the particle sizes leads to the increase in the specific surface area of the sample. The $\gamma-\mathrm{MgH}_{2}, \mathrm{TiH}_{1.924}$, and $\mathrm{MgO}$ formed during reactive mechanical grinding and their pulverization during reactive mechanical grinding are believed to make these effects stronger.

We believe that the hydrogen uptake-release cycling also creates defects, produces cracks and clean surfaces, and decreases particle sizes due to expansion (by hydrogen uptake) and contraction (by hydrogen release) of $\mathrm{Mg}$ [15-17]. We confirmed these effects with our result that the particles on the surfaces of relatively large particles, as shown in Fig. 9, are smaller than those of the sample after reactive mechanical grinding, as shown in Fig. 8.

Fig. 4 -Fig. 7 show that the activation of $\mathrm{MgH}_{2}-12 \mathrm{Ti}$ is not necessary. The quantity of hydrogen absorbed for $2.5 \mathrm{~min}, H_{\mathrm{a}}(2.5 \mathrm{~min}), H_{\mathrm{a}}(60 \mathrm{~min})$, the quantity of hydrogen released for $2.5 \mathrm{~min}, H_{\mathrm{d}}(2.5 \mathrm{~min})$, and $H_{\mathrm{d}}$ (60 $\mathrm{min})$ all decrease in general as $\mathrm{n}$ increases, showing that the cycling performance of $\mathrm{MgH}_{2}-12 \mathrm{Ti}$ is poor. Even though the particles on the surfaces of the relatively large ones after four hydrogen uptake-release cycles are smaller than those of the sample after reactive mechanical grinding, as shown in Fig. 9, the general decrease in $\mathrm{H}_{\mathrm{a}}(2.5 \mathrm{~min}), H_{\mathrm{a}}$ (60 min), $H_{\mathrm{d}}(2.5 \mathrm{~min})$, and $H_{\mathrm{d}}(60 \mathrm{~min})$ with increasing $\mathrm{n}$ suggests that the coalescence of cracks inside the particles occurs since the sample was maintained at relatively high temperatures $(573 \mathrm{~K}$ and $593 \mathrm{~K}$ ) during hydrogen uptakerelease cycling. We plan to perform further studies to improve the cycling performance of $\mathrm{MgH}_{2}-12 \mathrm{Ti}$ in our future work.

Fig. 12 shows the $H_{\mathrm{a}}$ vs. $t$ curves at $593 \mathrm{~K}$ in 12 bar $\mathrm{H}_{2}$ and the $H_{\mathrm{d}}$ vs. $t$ curves at $593 \mathrm{~K}$ in 1.0 bar $\mathrm{H}_{2}$ at $n=1$ for $\mathrm{MgH}_{2}$ after reactive mechanical grinding (named $\mathrm{MgH}_{2}$ after $\mathrm{RMG}$ ) and $\mathrm{MgH}_{2}-12 \mathrm{Ti} . \mathrm{MgH}_{2}$ after $\mathrm{RMG}$ has a higher initial hydrogen uptake rate and a larger $H_{\mathrm{a}}(60 \mathrm{~min})$ than $\mathrm{MgH}_{2}-12 \mathrm{Ti}$.

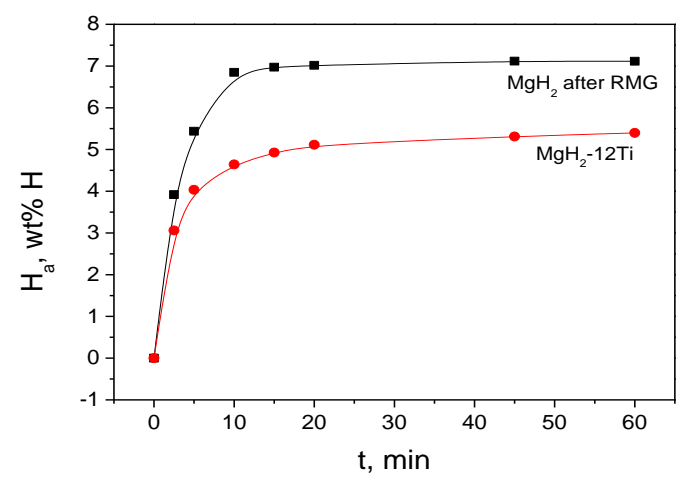

a

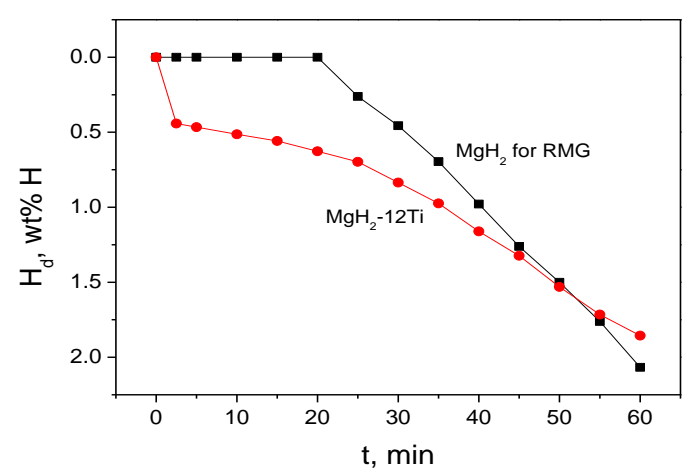

$\mathrm{b}$

Fig. 12. $\mathrm{a}-H_{\mathrm{a}}$ vs. $t$ curves at $593 \mathrm{~K}$ in 12 bar $\mathrm{H}_{2}$ and $\mathrm{b}-H_{\mathrm{d}}$ vs. $t$ curves at $593 \mathrm{~K}$ in 1.0 bar $\mathrm{H}_{2}$ at $n=1$ for $\mathrm{MgH}_{2}$ after $\mathrm{RMG}$ and $\mathrm{MgH}_{2}-12 \mathrm{Ti}$

$\mathrm{MgH}_{2}$ after RMG exhibits an incubation period of about $20 \mathrm{~min}$, after which $\mathrm{MgH}_{2}$ after RMG releases hydrogen quite rapidly. $\mathrm{MgH}_{2}$ after $\mathrm{RMG}$ releases $0.26 \mathrm{wt} . \% \mathrm{H}$ for $25 \mathrm{~min}$ and $2.07 \mathrm{wt} . \% \mathrm{H}$ for $60 \mathrm{~min}$. The initial hydrogen release rate of $\mathrm{MgH}_{2}-12 \mathrm{Ti}$ is slightly high 
and the hydrogen release rate of $\mathrm{MgH}_{2}-12 \mathrm{Ti}$ is low at $2.5 \mathrm{~min}$. The hydrogen release rates increase gradually after $2.5 \mathrm{~min}$ and are quite high at $50 \mathrm{~min} . \mathrm{MgH}_{2}-12 \mathrm{Ti}$ releases $0.44 \mathrm{wt} . \% \mathrm{H}$ for $2.5 \mathrm{~min}$ and $1.86 \mathrm{wt} . \% \mathrm{H}$ for $60 \mathrm{~min}$. These results show that the addition of Ti to $\mathrm{MgH}_{2}$ by reactive mechanical grinding facilitates the nucleation of $\mathrm{Mg}-\mathrm{H}$ solid solution in the hydrogenated sample.

Rizo-Acosta et al. [10] reported that the $0.975 \mathrm{MgH}_{2}+0.025 \mathrm{TiH}_{2}$ nanocomposite had the highest reversible capacity of $4.9 \mathrm{wt} . \% \quad \mathrm{H}$ among (1-y) $\mathrm{MgH}_{2}+\mathrm{yTiH}_{2}$ nanocomposites $(y=0,0.025,0.05,0.1$, 0.2 , and 0.3 ) which they prepared by reactive ball milling. Calizzi et al. [13] prepared $\mathrm{Mg}$ nanoparticles with the addition of $\mathrm{Ti}$ catalysts and reported that hydrogen desorption (desorption pressure $=8 \mathrm{mbar}$ ) and absorption (absorption pressure $=260$ mbar) was achieved at $473 \mathrm{~K}$ in about $2000 \mathrm{~s}$, while keeping a hydrogen storage capacity of $5.3 \mathrm{wt} \%$. Lu et al. [14] prepared nanocrystalline $\mathrm{Mg}$ and 90 wt. $\% \mathrm{Mg}+10$ wt.\% Ti hydrogen-storage alloys by reactive mechanical grinding and hydrogen uptake-release cycling five times. $90 \mathrm{wt} \% \mathrm{Mg}+10 \mathrm{wt} . \% \mathrm{Ti}$ had an improved hydrogen absorptioncapacity (3.63 wt.\%) compared with $\mathrm{Mg}$ (3.36 wt.\%). $\mathrm{MgH}_{2}-12 \mathrm{Ti}$ prepared in this work has a higher hydrogen storage capacity (an effective hydrogen storage capacity of $6.39 \mathrm{wt} . \%$ at $573 \mathrm{~K}$ in 12 bar $\mathrm{H}_{2}$ at $n=1$ ) than these reported composites.

\section{CONCLUSIONS}

Titanium was chosen as an additive to improve the hydrogen uptake and release properties of $\mathrm{MgH}_{2} .6,12$, and 15 weight percent Ti were added to $\mathrm{MgH}_{2}$ by milling in hydrogen (reactive mechanical grinding). Among the $\mathrm{MgH}_{2}-\mathrm{XTi}\left(\mathrm{x}=6,12\right.$, and 15) samples, $\mathrm{MgH}_{2}-12 \mathrm{Ti}$ had the highest initial hydrogen uptake and release rates and the largest $H_{\mathrm{a}}(60 \mathrm{~min})$ and $H_{\mathrm{d}}(60 \mathrm{~min})$. The hydrogen uptake and release properties of $\mathrm{MgH}_{2}-12 \mathrm{Ti}$ were studied in more detail because it had the highest initial hydrogen uptake and release rates and the largest quantities of hydrogen absorbed and released for $60 \mathrm{~min}$. At the first cycle, $\mathrm{MgH}_{2}-$ 12Ti absorbed $4.01 \mathrm{wt}$ \% $\mathrm{H}$ for $2.5 \mathrm{~min}$ and $6.39 \mathrm{wt} . \% \mathrm{H}$ for $60 \mathrm{~min}$ at $573 \mathrm{~K}$ in 12 bar $\mathrm{H}_{2}$, having an effective hydrogen storage capacity of 6.39 wt. $\%$. $\mathrm{MgH}_{2}-12 \mathrm{Ti}$ released $0.44 \mathrm{wt} . \% \mathrm{H}$ for $2.5 \mathrm{~min}$ and $1.86 \mathrm{wt} . \% \mathrm{H}$ for $60 \mathrm{~min}$ at $593 \mathrm{~K}$ in 1.0 bar $\mathrm{H}_{2}$. We believe that reactive mechanical grinding introduces imperfections, fabricates cracks, exposes fresh and clean surfaces, decreases the particle size, and disperses the additive among the particles. The $\gamma-\mathrm{MgH}_{2}, \mathrm{TiH}_{1.924}$, and $\mathrm{MgO}$ formed during reactive mechanical grinding and their pulverization during reactive mechanical grinding are believed to make these effects stronger. The hydrogen uptake-release cycling is also believed to induce effects similar to those of reactive mechanical grinding. The poor cycling performance of $\mathrm{MgH}_{2}-12 \mathrm{Ti}$ is attributed to the coalescence of cracks inside the particles because the sample was maintained at relatively high temperatures $(573 \mathrm{~K}, 593 \mathrm{~K}$, and $623 \mathrm{~K}$ ) during hydrogen uptake-release cycling. We plan to perform further studies to improve the cycling performance of $\mathrm{MgH}_{2}-12 \mathrm{Ti}$ in our future work.

\section{Acknowledgements}

This research was supported by Basic Science Research Program through the National Research Foundation of Korea (NRF) funded by the Ministry of Education (grant number NRF2017R1D1A1B03030515).

\section{REFERENCES}

1. Song, M.Y., Kwak, Y.J. Effects of $\mathrm{Zn}\left(\mathrm{BH}_{4}\right)_{2}$, Ni, and/or Ti Doping on the Hydrogen-Storage Features of $\mathrm{MgH}_{2}$ Korean Journal of Metals and Materials 57 (3) 2019: pp. $176-183$.

https://doi.org/10.3365/KJMM.2019.57.3.176

2. Song, M.Y., Choi, E., Kwak, Y.J. Preparation of a MgBased Alloy with a High Hydrogen-Storage Capacity by Adding a Polymer CMC via Milling in a Hydrogen Atmosphere International Journal of Hydrogen Energy 44 (7) 2019: pp. 3779-3789.

https://doi.org/10.1016/j.ijhydene.2018.12.081

3. Song, M.Y., Choi, E., Kwak, Y.J. Increase in the Dehydrogenation Rate of Mg-CMC (Carboxymethylcellulose, Sodium Salt) by Adding Ni via Hydride-Forming Milling Metals and Materials International 25 2019: pp. 516-527. https://doi.org/10.1007/s12540-018-0188-2

4. Song, M.Y., Kwak, Y.J., Lee, S.H. $\mathrm{TiCl}_{3}$ and Ni-Added $\mathrm{Mg}$ Prepared by Reactive Mechanical Grinding Processing and Comparison with $\mathrm{Fe}_{2} \mathrm{O}_{3}$ and $\mathrm{Ni}$-Added $\mathrm{Mg}$ Journal of Ceramic Processing Research 20 (2) 2019: pp. 173-181. https://doi.org/10.36410/jcpr.2019.20.2.173

5. Song, M.Y., Choi, E., Kwak, Y.J. Nickel, Graphene, and Yttria-Stabilized Zirconia (YSZ)-Added Mg by Grinding in Hydrogen Atmosphere for Hydrogen Storage Metals 9 (12) 2019: pp. $1-16$. https://doi.org/10.3390/met9121347

6. Song, M.Y., Choi, E., Kwak, Y.J. Hydrogenation and Dehydrogenation Behaviors of $\mathrm{Mg}_{2} \mathrm{Ni}$ Synthesized by Sintering Pelletized Mixtures under an Ar Atmosphere Journal of Nanoscience and Nanotechnology 19(10) 2019: pp.6571-6579. https://doi.org/10.1166/jnn.2019.17082

7. Liang, G., Huot, J., Boily, S., Van Neste, A., Schulz, R. Catalytic Effect of Transition Metals on Hydrogen Sorption in Nanocrystalline Ball Milled $\mathrm{MgH}_{2}-\mathrm{Tm}(\mathrm{Tm}=\mathrm{Ti}, \mathrm{V}, \mathrm{Mn}$, $\mathrm{Fe}$ and Ni) Systems Journal of Alloys and Compounds 292 (1-2) 1999: pp. 247-252.

https://doi.org/10.1016/S0925-8388(99)00442-9

8. Asano, K., Etsuo Akiba, E. Direct Synthesis of Mg-Ti-H FCC Hydrides from $\mathrm{MgH}_{2}$ and Ti by Means of Ball Milling Journal of Alloys and Compounds $481(1-2)$ 2009: pp. L8-L11. https://doi.org/10.1016/j.jallcom.2009.02.152

9. Korablov, D., Torben, F.B., Jensen, R. Kinetics and Thermodynamics of Hydrogenation-Dehydrogenation for $\mathrm{Mg}-25 \% \mathrm{TM} \quad(\mathrm{TM}=\mathrm{Ti}, \quad \mathrm{Nb}$ or $\mathrm{V})$ Composites Synthesized by Reactive Ball Milling in Hydrogen International Journal of Hydrogen Energy 43 (34) 2018: pp. $16804-16814$. https://doi.org/10.1016/j.ijhydene.2018.05.091

10. Rizo-Acosta, P., Cuevas, F., Latroche, M. Optimization of $\mathrm{TiH}_{2}$ Content for Fast and Efficient Hydrogen Cycling of $\mathrm{MgH}_{2}-\mathrm{TiH}_{2}$ Nanocomposites International Journal of Hydrogen Energy 43 2018: pp. 16774-16781. https://doi.org/10.1016/j.ijhydene.2018.04.169 
11. Maweja, K., Phasha, M., van der Berg, N. Microstructure and Crystal Structure of an Equimolar $\mathrm{Mg}-\mathrm{Ti}$ Alloy Processed by Simoloyer High-Energy Ball Mill Powder Technology 199 (3) 2010: pp. 256-263.

https://doi.org/10.1016/j.powtec.2010.01.014

12. Korablov, D., Besenbacher, F., Jensen, T.R. Ternary Compounds in the Magnesium-Titanium Hydrogen Storage System International Journal of Hydrogen Energy 39 (18) 2014: pp. $9700-9708$. https://doi.org/10.1016/j.ijhydene.2014.03.141

13. Calizzi, M., Chericoni, D., Jepsen, L.H., Jensen, T.R., Pasquini, L. Mg-Ti Nanoparticles with Superior Kinetics for Hydrogen Storage International Journal of Hydrogen Energy 41 2016: pp. 14447-14454. https://doi.org/10.1016/j.ijhydene.2016.03.071

14. Lu, W.C., Ou, S.F., Lin, M.H. Wong, M.F. Hydriding Characteristics of $\mathrm{Mg}-\mathrm{Ti}$ Alloys Prepared by Reactive Mechanical Grinding and Hydrogen Pulverization Journal of Alloys and Compounds 664 2016: pp. 193-198. https://doi.org/10.1016/j.jallcom.2015.12.064

15. Biasetti, A., Meyer, M., Mendoza Zelis, L. Formation Kinetics and Microstructure of Mg-Ti Hydrides Made by Reactive Ball Milling International Journal of Hydrogen Energy 39 2014: pp. 8767-8771. https://doi.org/10.1016/j.ijhydene.2013.12.034

16. Biasetti, A., Meyer, M., Mendoza Zelis, L. Hydriding Kinetics of $\mathrm{MgTiH}_{2}$ Fine Dispersions Obtained by Mechanosynthesis Powder Technology 307 2017: pp. $145-152$. https://doi.org/10.1016/j.powtec.2016.11.026

17. Daryani, M., Simchi, A., Sadati, M., Mdaah Hosseini, H., Targholizadeh, H., Khakbiz, M. Effects of Ti-Based Catalysts on Hydrogen Desorption Kinetics of Nanostructured Magnesium Hydride International Journal of Hydrogen Energy 39 2014: pp. 21007-21014. https://doi.org/10.1016/j.ijhydene.2014.10.078

18. Alsabawi, K., Gray, E., Mac, A., Webb, C.J. The Effect of Ball-Milling Gas Environment on the Sorption Kinetics of $\mathrm{MgH}_{2}$ with/without Additives for Hydrogen Storage International Journal of Hydrogen Energy $44(5)$ 2019: pp. 2976-2980.

https://doi.org/10.1016/j.ijhydene.2018.12.026
19. Park, H.R., Kwak, Y.J., Song, M.Y. Increase in the Hydrogen-Sorption Rates and the Hydrogen-Storage Capacity of $\mathrm{MgH}_{2}$ by Adding a Small Proportion of $\mathrm{Zn}\left(\mathrm{BH}_{4}\right)_{2} \quad$ Korean Journal of Metals and Materials 55 (9) 2017: pp. 657-663. https://doi.org/10.3365/KJMM.2017.55.9.657

20. Hong, S.H., Kwak, Y.J., Song, M.Y. Enhancement of the Hydrogen-Storage Characteristics of $\mathrm{Mg}$ by Adding $\mathrm{Mg}_{2} \mathrm{Ni}$ and $\mathrm{Ni}$ to $\mathrm{MgH}_{2}$ via High Energy Ball Milling in Hydrogen Atmosphere Korean Journal of Metals and Materials 56 (1) 2018: pp. 59-65. https://doi.org/10.3365/KJMM.2018.56.1.59

21. Hong, S.H., Song, M.Y. Hydrogen Absorption and Release Properties of $\mathrm{MgH}_{2}, \mathrm{Mg}_{2} \mathrm{Ni}$, and Ni-added $\mathrm{Mg}$ via Reactive Mechanical Grinding Korean Journal of Metals and Materials $56(2)$ 2018: pp. 155-162. https://doi.org/10.3365/KJMM.2018.56.2.155

22. Song, M.Y., Kwak, Y.J. Comparison of the Hydrogen Release Properties of $\mathrm{Zn}\left(\mathrm{BH}_{4}\right)_{2}$-Added $\mathrm{MgH}_{2}$ Alloy and $\mathrm{Zn}\left(\mathrm{BH}_{4}\right)_{2}$ and $\mathrm{Ni}$-added $\mathrm{MgH}_{2}$ Alloy Korean Journal of Metals and Materials 56 (3) 2018: pp. 244-251. https://doi.org/10.3365/KJMM.2018.56.3.244

23. Song, M.Y., Choi, E., Kwak, Y.J. Development of a MgBased Alloy with a Hydrogen-Storage Capacity of 7 wt.\% by Adding a Polymer CMC via Transformation-Involving Milling Korean Journal of Metals and Materials 56 (5) 2018: pp. $392-399$. https://doi.org/10.3365/KJMM.2018.56.5.392

24. Song, M.Y., Kwak, Y.J., Choi, E. Hydrogen Storage Properties of Mg-Graphene Composites Korean Journal of Metals and Materials 56 (7) 2018: pp. 524-531. https://doi.org/10.3365/KJMM.2018.56.7.524

25. Song, M.Y., Kwak, Y.J. Hydrogen Uptake and Release Characteristics of $\mathrm{Mg}-\mathrm{xTaF}_{5}-\mathrm{xVCl}_{3}(\mathrm{x}=1.25,2.5$, and 5) Korean Journal of Metals and Materials $56(8)$ 2018: pp. $611-619$. https://doi.org/10.3365/KJMM.2018.56.8.611

26. Song, M.Y., Choi, E., Kwak, Y.J. Raising the Dehydrogenation Rate of a Mg-CMC (Carboxymethylcellulose, Sodium Salt) Composite by Alloying Ni via Hydride-Forming Milling Korean Journal of Metals and Materials 56 (8) 2018: pp. 620-627. https://doi.org/10.3365/KJMM.2018.56.8.620 